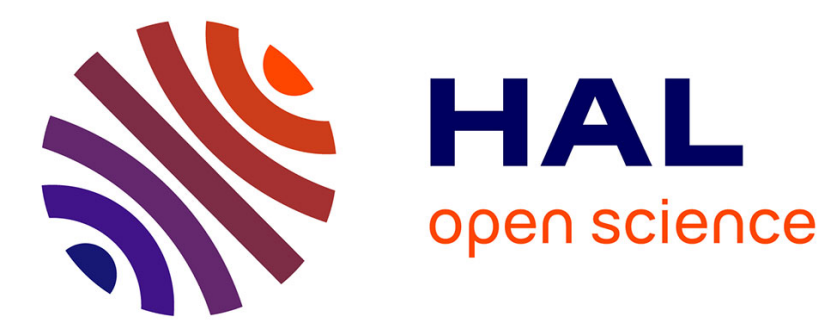

\title{
New polymeric materials with interferential optical properties
}

\author{
L. Ghannam, H. Garay, Jeanne François, Laurent Billon
}

\section{To cite this version:}

L. Ghannam, H. Garay, Jeanne François, Laurent Billon. New polymeric materials with interferential optical properties. Macromolecular Chemistry and Physics, 2007, 208 (13), pp.1469-1479. 10.1002/macp.200700069 . hal-01582042

\section{HAL Id: hal-01582042 \\ https://hal.science/hal-01582042}

Submitted on 1 Jun 2021

HAL is a multi-disciplinary open access archive for the deposit and dissemination of scientific research documents, whether they are published or not. The documents may come from teaching and research institutions in France or abroad, or from public or private research centers.
L'archive ouverte pluridisciplinaire HAL, est destinée au dépôt et à la diffusion de documents scientifiques de niveau recherche, publiés ou non, émanant des établissements d'enseignement et de recherche français ou étrangers, des laboratoires publics ou privés. 


\title{
New Polymeric Materials with Interferential Optical Properties
}

\author{
Leïla Ghannam, Hélène Garay, Jeanne François, Laurent Billon*
}

Nature provides a wide pallet of colors but also a wide number of fascinating optical phenomena such as nacre or interferential effects, which can be observed in insect wings and shellfish. The origin of such effects is attributed to the presence of highly ordered arrangements in Nature's materials. The aim of this paper is to focus some new approaches and advances for creating interferential optical phenomena as observed in nature by tuning or modeling the polymer architectures or organization.

A relatively simple method is described to prepare organic/inorganic hybrid pigments constituted of mica platelets and adsorbed polymer layers. It is shown that the color of mica is changed upon polymer adsorption, and when one of the copolymer sequences includes a dye, its color is influenced by the chemical properties of the mica surface. Moreover, a new facile route is presented to obtain highly ordered surfaces using ionomer macromolecular designs synthesized in one step by controlled radical polymerization. The preparation of films with very regular pore size and spatial organization is successfully realized by using ionomer solutions. An original property of these films with an iridescent color obtained by light diffraction as a result of the optical interferences of sunlight with the periodic honeycomb structures is presented.

All these new materials based on polymeric controlled structures can reproduce nature by creating an optical interferential and iridescent material, which offers new fascinating applications as original bio-mimetic materials on inorganic surfaces.

\footnotetext{
L. Ghannam, J. François, L. Billon Institut Pluridisciplinaire de Recherche sur l'Environnement et les Matériaux, Equipe de Physico-Chimie des Polymères, IPREM/EPCP CNRS UMR 5254, Université de Pau et Pays de l'Adour, France E-mail: laurent.billon@univ-pau.fr

H. Garay

Centre de Matériaux de Grande Diffusion, Ecole de Mines d'Alès-Pau, Hélioparc Pau-Pyrénées, 2 avenue Président Angot, 64053 PAU CEDEX 9, France

L. Ghannam

Université Libanaise, Faculté des Sciences, Département de Chimie et Biochime, Beyrouth, Liban, France
}

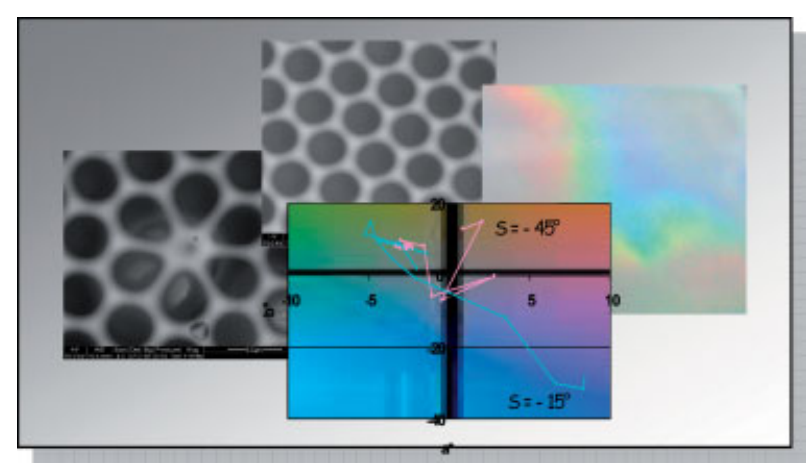

\section{Introduction}

Nature provides us not only a wide pallet of colours but also a wide number of fascinating optical phenomena, such as the nacre or interferential effect, which can be observed in insect wings and shellfishes. The origin of such an effect is attributed to the presence of highly ordered arrangements in Nature's materials. The physical understanding of such phenomena can lead to original ideas for the creation of new materials that exhibit specific visual properties. Thus interferential colors can be obtained by different physical processes of light diffraction as a result 

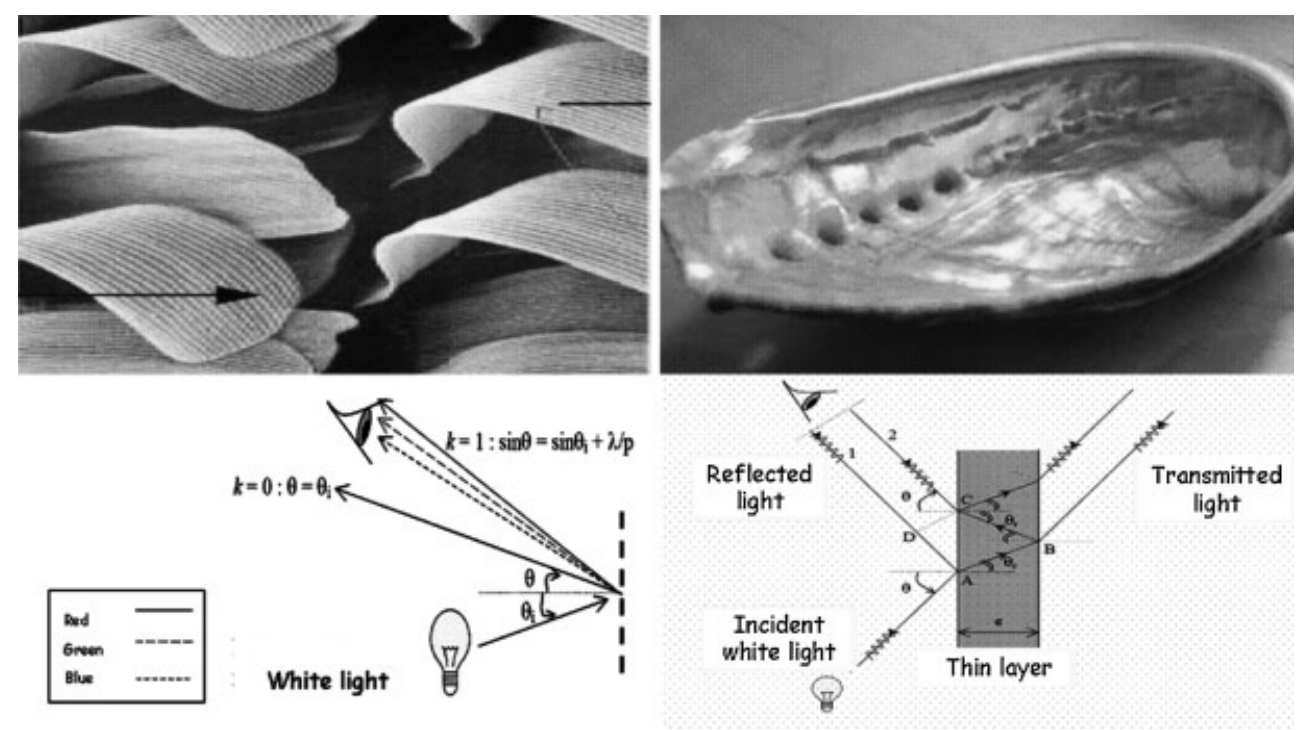

Figure 1. Interferential optical phenomena observed in Nature by light diffraction or light multi-reflexion, respectively, for scales of butterfly wings (left) and shell fish (right).

of highly structured systems or by superposition of light multi-reflexion created on thin layers (Figure 1).

Thanks to their properties, one of the most interesting goals in modern material science is to determine how is it possible to create some interferential optical phenomena as seen in Nature using the self-assembled monolayers of polymers on solid substrates with the combination of modern methods of synthesis. ${ }^{[1-3]}$ The origin of such optical phenomena is the existence of highly ordered structures in materials.

The aim of this paper is to report on some new approaches and advances, recently developed in our team, for creating interferential optical phenomena by tuning or modeling polymer architectures and organization. The elaboration of lamellar structured systems (onedimensional, 1D) and well structured/ordered systems (two-dimensional, 2D) based on hybrid inorganic/organic particles and honeycomb structures are presented.

\section{Lamellar Structured System: Hybrid Inorganic/ Organic Particles}

Polymerization with surface-bound initiators is a potentially flexible and convenient method for modifying the surface properties of inorganic materials and preparing novel inorganic/organic hybrids, ${ }^{[4]}$ especially from mica flakes, which conserve their lamellar structure under different and strong conditions. Recently, the surfaceinitiated classical or controlled free radical polymerization techniques of polystyrene have been established from inorganic particles. Notably, Suter et al. have described the graft free radical polymerization of styrene on a mica surface. $^{[5]}$
Moreover, the synthesis of well-defined grafted homopolymers and copolymers has been achieved by a controlled free-radical polymerization (CRP) process. ${ }^{[6]}$ Among the possible techniques, nitroxide-mediated polymerization (NMP) is one of the efficient methods to elaborate hybrid inorganic/organic materials. ${ }^{[7]}$ Indeed, Ghannam et al. have demonstrated the possibility to synthesize poly(butyl acrylate) (PBA) from the surface of mica platelets and create a homogeneous brush of PBA. ${ }^{[8]}$

In the first part of the present work, the ability of NMP has been exploited to provide block copolymers from an inorganic silica surface. ${ }^{[9]}$ The preparation of mica/block copolymer composites then required the following steps: i) modification of the dye (alizarin) to prepare a vinyl monomer able to copolymerize with styrene, ii) polymerization of butyl acrylate (BA) on a mica surface after adsorption of a cationic initiator, and iii) polymerization of a statistical copolymer of styrene and the modified dye monomers from the PBA used as a macroinitiator (Figure 2).

Initially, this study will try to reproduce a multi-layered structure by the superposition of two layers of organic compounds at the surface of a lamellar silicate.

\section{Highly Ordered System: Honeycomb-Like Structure}

Because of their very interesting properties, self-assembled monolayers of different chemical species on various solid substrates are becoming an important theme of the modern material science.

Among the various types of organizations already described, the honeycomb 2D structure is one of the most interesting and fascinating. They were discovered by Francois et al., who have shown that fast evaporation of 


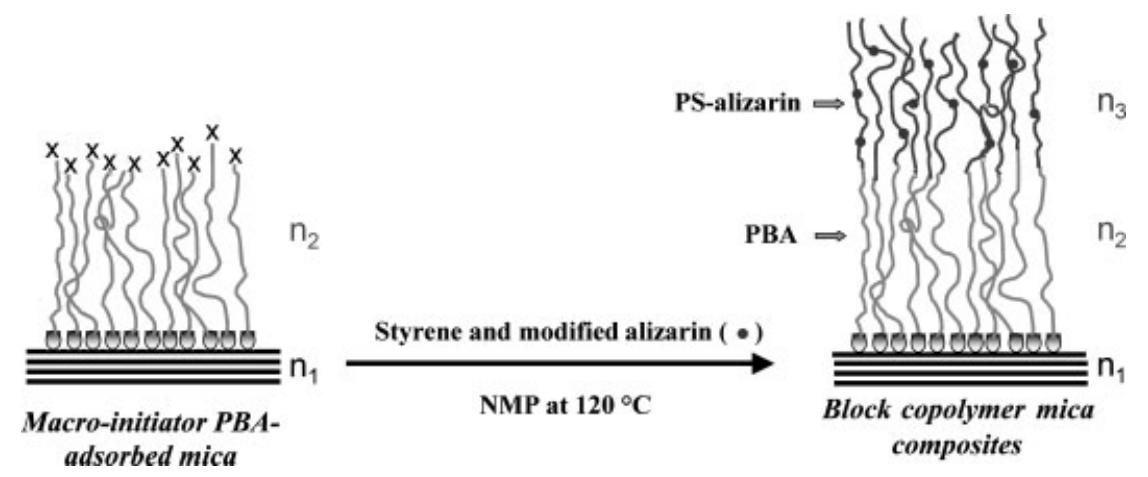

Figure 2. Synthesis of diblock copolymers by in-situ NMP as hybrid inorganic/organic particles or a lamellar structured system $\left(n_{1}, n_{2}\right.$, and $n_{3}$ correspond to the refractive index of the three layers of the composite).

thin layers of polystyrene (PS) solutions on glass platelets leads to solid films organized over long distances with an hexagonal 2D array of holes of 1-5 $\mu$ m diameter separated by $0.5-1 \mu \mathrm{m}$ of pure PS. ${ }^{[10-12]}$ These samples were prepared by anionic polymerization (AP), which is experimentally difficult and limited to few monomers. It is well known that CRP now provides greater opportunities to obtain polymers with a much easier experimental route and for a greater number of monomers. Moreover, if CRP is more flexible than anionic polymerization, up to now, the polymer architectures used have still been complexes. ${ }^{[13]}$ Thanks to the potential applications of these organized films, several authors have again undertaken these studies and extended them to other polymer architectures ${ }^{[14-18]}$ and the fabrication of such highly ordered hexagonal arrays has been described in a recent review. ${ }^{[19]}$

In the last part of this paper, a novel and facile route will be presented to obtain highly ordered self-assembled honeycomb films from ionomer structures. Finally, preliminary results on the visual aspects of these composites will be also presented.

\section{Experimental Part}

\section{Lamellar Structured System: Hybrid Inorganic/ Organic Particles}

\section{Materials}

The Soft Mica ${ }^{\circledR}$ samples were received from the Comptoir des Minéraux et des Matières Premières (France). The monomers (Aldrich) and solvents were used as received. The dye chosen for this study was 'alizarin' which is an anthraquinone.

\section{Alizarin Modification}

In order to incorporate chromophore groups into the polymer chains, it was necessary to prepare alizarin-based vinyl monomers. The experimental method has been described elsewhere. ${ }^{[20]}$ The comparison of UV-vis absorption spectra of alizarin before and after chemical modification showed that the absorption band of
$\mathrm{C}=\mathrm{O}$ at $436 \mathrm{~nm}$ was shifted to $390 \mathrm{~nm}$ and a new absorption band appeared at $329 \mathrm{~nm}$, characteristic of $\mathrm{C}=\mathrm{C}$. A complementary ${ }^{1} \mathrm{H}$ and ${ }^{13} \mathrm{C}$ NMR study was performed and showed the appearance of carbonyl and acrylic functions, thus confirming the success of alizarin modification. Nevertheless, the average number of acrylic units per alizarin molecule was calculated by ${ }^{1} \mathrm{H}$ NMR spectroscopy to be 0.5 , with the presence of two mono-modified alizarin structures in the proportion of 35/65 for ortho/meta-modified hydroxy groups.

\section{Polymerization on Mica Surface}

In order to obtain poly( $n$-butyl acrylate)-block-(styrene-alizarin) [PBA- $b-\mathrm{P}(\mathrm{S}-\mathrm{A})]$ at the surface of mica, two phases were necessary: i) modification of the mica surface by a macroinitiator of PBA using NMP polymerization of BA, and ii) copolymerization of styrene/ modified dye from the PBA macroinitiator. ${ }^{[8]}$ For this purpose, a mixture of mica particles with adsorbed PBA (100 mg), styrene (estimated ratio $[\mathrm{S}] /[\mathrm{PBA}]=30000)$, and modified dye $([\mathrm{S}] /$ [alizarin] $=333$ ) was heated at $120^{\circ} \mathrm{C}$ for $2 \mathrm{~h}$.

After reaction, the dispersion was poured into ethanol to precipitate both free polymer and mica with adsorbed polymer. Following filtration and drying, the polymer-mica mixture was extracted several times with toluene to remove the non-adsorbed polymer. Two types of copolymer were found: copolymer 'bound' to the mica (not removed from the mica either during polymerization or by toluene extraction) and 'free' copolymer precipitated in ethanol. The solid phase, which consisted of mica covered by adsorbed polymer, was dried at room temperature under vacuum.

\section{Characterization Methods}

${ }^{1} \mathrm{H}$ NMR spectra were recorded at $400 \mathrm{MHz}$ on a Bruker Advanced $\mathrm{AM} 400$ spectrometer in $\mathrm{CDCl}_{3}$ and the chemical shifts $(\delta)$ in ppm were referred to internal tetramethylsilane. UV-vis spectra were recorded using a Shimadzu UV-2101 PC spectrometer. Thermal gravimetric analysis (TGA) was carried out using a System TA 2950 apparatus, to determine the amount of bound polymer chains adsorbed onto the mica surface over a temperature range of 30$800^{\circ} \mathrm{C}$ at a scan rate of $10^{\circ} \mathrm{C} \cdot \mathrm{min}^{-1}$ in air. Glass transition temperatures $\left(T_{\mathrm{g}}\right)$ were measured using a differential scanning calorimeter (DSC), TA series-[Q100]. Samples ( $\approx 5 \mathrm{mg}$ ) were weighed and scanned at $20^{\circ} \mathrm{C} \cdot \mathrm{min}^{-1}$ under dry nitrogen (flow rate: $50 \mathrm{~mL}$. $\min ^{-1}$ ). The reported glass transition temperatures were determined from the second heating run and were taken as the 
mid-point of the $\Delta H / \mathrm{d} t$ step in the DSC spectra. The molecular weights and the polydispersity indexes of the free polymers were determined by size exclusion chromatography (SEC), using a 2690 Waters System with tetrahydrofuran (THF) as the mobile phase. Molecular weights were calculated relative to polystyrene standards. The X-Ray diffraction (XRD) data from powder samples were recorded using reflection geometry with pseudo-focusing known as Bragg-Brentano. They were collected at room temperature on an INEL CPS 120 powder diffractometer (calibrated with NAC $\left.\left(\mathrm{Na}_{2} \mathrm{Ca}_{3} \mathrm{Al}_{2} \mathrm{~F}_{14}\right)\right)$ with monochromatized $\mathrm{Cu} \mathrm{K} \alpha\left(\lambda_{\text {meas. }}=\right.$ $0.15406 \mathrm{~nm}$ ) radiation (30 to $40 \mathrm{kV}$ ).

\section{Highly Ordered System: Honeycomb-Like Structure}

\section{Materials}

Ionomer polystyrene (PS) was applied to the fabrication of microporous films. This polymer was synthesized by NMP in bulk using two commercially available products: VAZO 56 (2,2'-azobis-(2amidinopropane) dihydrochloride) (Dupont-USA) as initiator and the $N$-tert-butyl-(1-diethyl-phosphono,2,2-dimethylpropyl) nitroxide SG1 as counter radical (Arkema-France). Thanks to the combination of NMP and this initiator, the polymer receives a cationic function on its end, which gives it an ionomer character. The molecular weight and the polydispersity index (PDI) (determined by SEC) of the PS polymer was $28000 \mathrm{~g} \cdot \mathrm{mol}^{-1}$ and 1.20 , respectively.

\section{Film Preparation}

Polymer was end-capped by a cationic function and the ionomer behaviour formed stars in the solvent carbon disulphide ( $\mathrm{bp}=$ $46^{\circ} \mathrm{C}$ ) because of the non-solubility of the cationic end chains. The $\mathrm{CS}_{2}$ solution of the ionomer (concentration of polymer $\left(C_{\mathrm{p}}\right)=$ $4.5 \times 10^{-4} \mathrm{~mol} \cdot \mathrm{L}^{-1}$ ) was spread over a mica surface. The solution was evaporated at room temperature just under the air flow of a hood.

\section{Observation of Surface Morphology}

The microporous films were characterized by optical microscopy (BH-2, Olympus) and scanning electron microscopy (SEM, Oxford Instruments, INCA ENERGY 350).

\section{Results and Discussion}

\section{Lamellar Structured System: Hybrid Inorganic/ Organic Particles}

The elaboration of a multi-layered composite by block copolymerization from the mica surface is considered. In order to create a homogeneous brush of PBA, an initiator possessing a cationic function able to interact with the negative charge of mica has been adsorbed on its surface. BA has then been polymerized by NMP. The results of the two first steps of the hybrid inorganic/organic pigment elaboration, based on the exchange of the cations by an

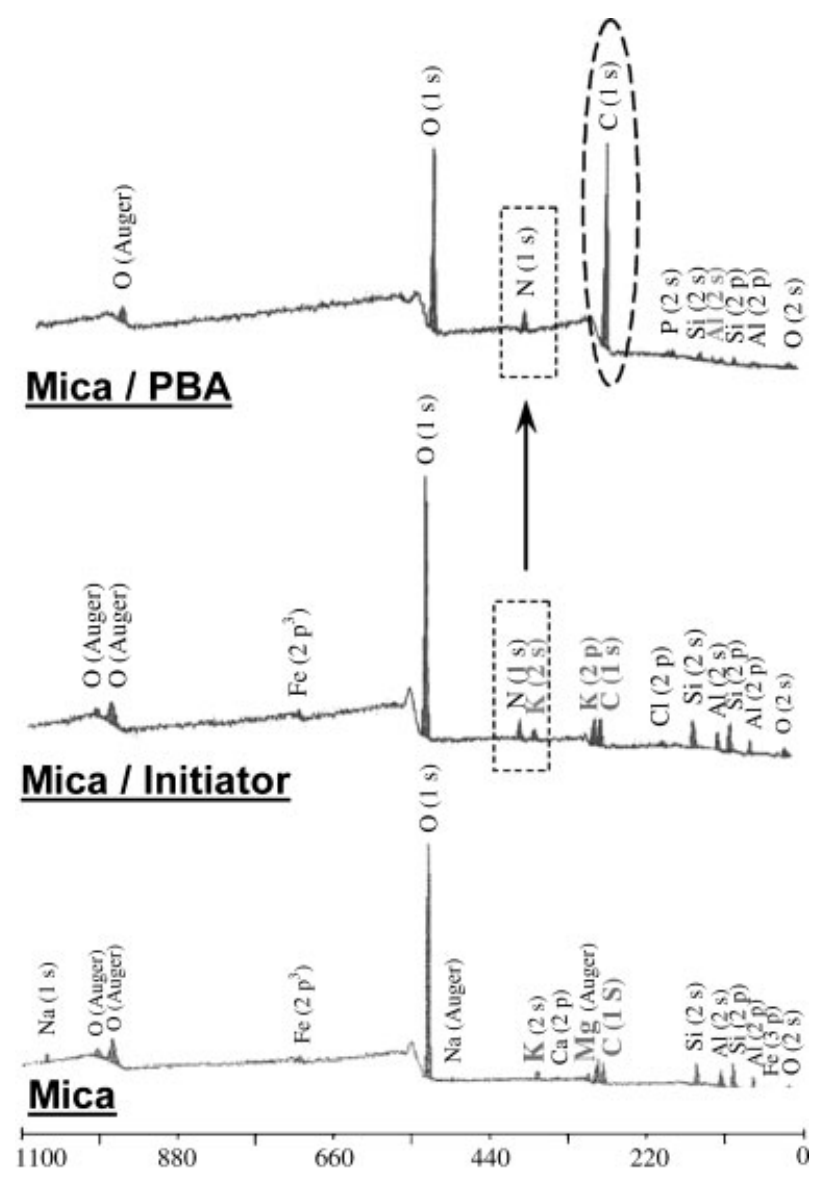

Figure 3. XPS spectra of PBA ( $24 \mathrm{~h})$-coated mica, AlBA-adsorbed mica and soft mica from top to bottom, respectively (insert: $\mathrm{P}(2 \mathrm{p})$ signal of SG1 end-capped PBA).

azoic initiator, and finally the first BA block polymerization are summarized in Figure 3.

The signals of pure mica show the presence of silicate [152 eV, Si (2s); $102 \mathrm{eV}, \mathrm{Si}(2 \mathrm{p})]$, aluminate [110 eV, Al(2s); $74 \mathrm{eV}, \mathrm{Al}(2 \mathrm{p})]$, and oxygen atoms [531 eV, O(1s)]. After adsorption of AIBA (azoic initiator), two new signals appear that arise from the carbon [285 eV, C(1s)] and nitrogen atoms [399 eV, N(1s)] of the azo compound, by mica cation exchange. A comparison of the XP spectra of the initiator monolayer and the adsorbed PBA shows a strong enhancement of the carbon $[\mathrm{C}(1 \mathrm{~s})]$ and oxygen [O(1s)] atoms signals at 285 and $531 \mathrm{eV}$, respectively. Moreover, some additional information is provided by the presence of peaks associated with the phosphorus atoms $[\mathrm{P}(2 \mathrm{p}) ; 133.4 \mathrm{eV}]$ characteristic of the $\mathrm{P}-\mathrm{O}$ function of the counter-radical SG1 (Figure 4).

The presence of the end-capped nitroxide macromolecular chains is confirmed by the presence of the large peak at $133.4 \mathrm{eV}$ on the spectrum of mica modified by polymer, which provides the opportunity in a third step to elaborate multi-layered organic/inorganic particles. The ability of NMP has been exploited to provide block copolymers. Indeed 


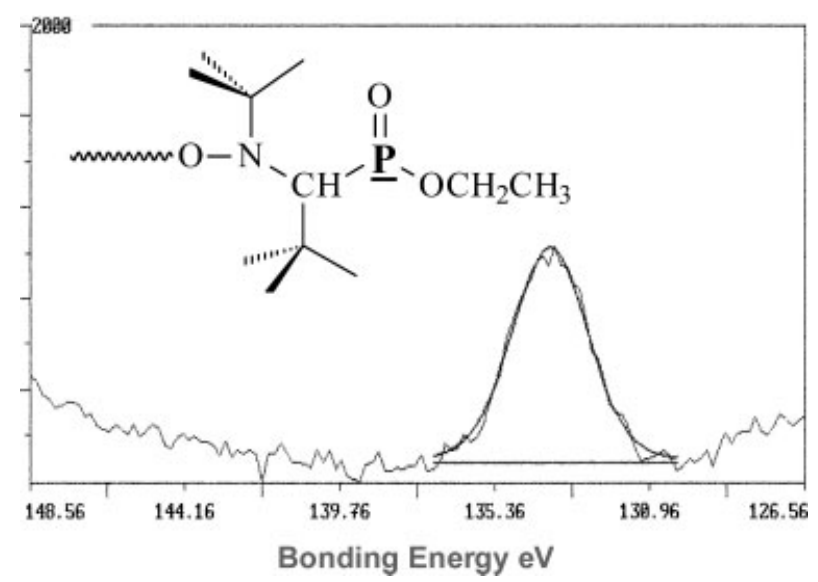

Figure 4. Zoom of the PBA XPS spectra of the phosphorous atom $\mathrm{P}(2 \mathrm{p})$ : signal of nitroxide $\mathrm{SG} 1$ end-capped PBA.

a block copolymer PBA-b-PS (elastomer/thermoplastic) was synthesized at the surface of the mica particles. The first sequence was the homo-PBA and the second one was a statistical copolymer of styrene and a vinyl monomer bearing a chromophore group (alizarin, derivative A), $\mathrm{P}(\mathrm{S}-\mathrm{A})$. The presence of the chromophore group allowed absorption in the visible light range. On the other hand, a strong segregation between the PBA and P(S-A) sequences was expected because of their significantly different solubility parameters, thus they should be incompatible. ${ }^{[9]}$ The apparent numberaverage molecular weights as well as the molar mass distribution of both the macro-initiator and the free copolymer desorbed from the mica surface during reaction were measured by SEC. The values of the number-average molecular weights (PS equivalent) are reported in Table 1.

The PBA-precursor extension is demonstrated by the polymerization of the other monomers (S/A). The final diblock copolymer shows neither shoulder nor peak in the low-molecular-weight range, which indicates the exten- sion efficiency of the first PBA block to form a diblock copolymer PBA- $b-\mathrm{P}(\mathrm{S}-\mathrm{A})$. However, a high polydispersity value was obtained for the diblock copolymer, PDI $=2.29$, which may be explained by the uncontrolled radical polymerization because of the high initial ratio [S]/[PBA] during the last step of the pigment elaboration. The copolymer structure has been demonstrated by the signal at 6-8 ppm, which corresponds to the phenyl groups of PS. This spectrum did not show alizarin peaks because the latter was in a small quantity compared with PBA and PS (0.3 mol-\% of alizarin per mol of styrene). The molar composition of the copolymer was estimated by integration of the peaks to $16 \% \mathrm{PBA}$ and $84 \% \mathrm{P}(\mathrm{S}-\mathrm{A})$. If one considers the value of $\bar{M}_{n}$ for the PBA macroinitiator $\left(\bar{M}_{\mathrm{n}}=30000 \mathrm{~g} \cdot \mathrm{mol}^{-1}\right)$, such a composition should correspond to $\bar{M}_{\mathrm{n}}=137000 \mathrm{~g} \cdot \mathrm{mol}^{-1}$ for the copolymer, which was in good agreement with the SEC results (Table 1 ).

Moreover, the UV-vis spectrum of free diblock copolymer shows the peak characteristic of PS at $257 \mathrm{~nm}$, a shoulder at about $280 \mathrm{~nm}$, and two small absorption bands at 329 and $390 \mathrm{~nm}$, which corresponds to linked alizarin (Figure 5). The incorporation of the dye-based monomer in the second PS block of the copolymer is indicated by these bands.

The adsorption density of copolymer on the mica platelets can be calculated from the loss of weight of the composite as a result of the degradation of the copolymer that occurs in TGA experiments between 30 and $800^{\circ} \mathrm{C}$. The amount of adsorbed copolymer was found to be $0.107 \mathrm{mg}$ per $\mathrm{mg}$ of mica, which corresponded to 0.07 molecules per $\mathrm{nm}^{2}$ of mica surface. It may be noted that the adsorption density of the polymer chains was lower than that of the PBA macro-initiator on the mica surface (0.6 molecules per $\left.\mathrm{nm}^{2}\right) .{ }^{[8]}$ This phenomenon was related to desorption of the macromolecular chains and a continuous expulsion with time, probably because of an increase

Table 1. Adsorption density $\left(\sigma_{\text {ads }}\right)$ values for hybrid inorganic/organic pigments polymer/mica.

\begin{tabular}{|c|c|c|c|c|c|c|}
\hline \multirow[t]{3}{*}{$\begin{array}{l}\text { Hybrid organic/ } \\
\text { inorganic pigments }\end{array}$} & \multicolumn{2}{|c|}{$\begin{array}{l}\text { Macromolecular } \\
\text { dimensions }\end{array}$} & \multicolumn{2}{|c|}{$\sigma_{\text {ads }}$} & \multicolumn{2}{|c|}{$\sigma_{\text {ads }}$} \\
\hline & \multirow{2}{*}{$\frac{\bar{M}_{\mathrm{n}}}{\mathrm{g} \cdot \mathrm{mol}^{-1}}$} & \multirow[t]{2}{*}{ PDI } & \multicolumn{2}{|c|}{$\mu \mathrm{mol} \cdot(\mathrm{mg} \text { of mica })^{-1}$} & \multicolumn{2}{|c|}{ molecules $\cdot \mathbf{n m}^{-2}$} \\
\hline & & & Polymer & $\begin{array}{l}\text { Modified } \\
\text { alizarine }\end{array}$ & Polymer & $\begin{array}{l}\text { Modified } \\
\text { alizarine }\end{array}$ \\
\hline PBA & 30000 & 1.14 & $6.0 \times 10^{-3}$ & $N / A^{a)}$ & 0.6 & $\mathrm{~N} / \mathrm{A}^{\mathrm{A}}$ \\
\hline PBA- $b-\mathrm{P}(\mathrm{S}-\mathrm{A})$ & 157000 & 2.29 & $6.8 \times 10^{-4}$ & $3.0 \times 10^{-4}$ & 0.07 & 0.28 \\
\hline $\mathrm{P}(\mathrm{S}-\mathrm{A}) 1$ & 3200 & 1.15 & $4.4 \times 10^{-3}$ & $1.3 \times 10^{-3}$ & 0.448 & 0.135 \\
\hline $\mathrm{P}(\mathrm{S}-\mathrm{A}) 2$ & 8700 & 1.15 & $5.4 \times 10^{-3}$ & $4.5 \times 10^{-3}$ & 0.550 & 0.456 \\
\hline $\mathrm{P}(\mathrm{S}-\mathrm{A}) 4$ & 24000 & 1.23 & $2.9 \times 10^{-3}$ & $6.7 \times 10^{-3}$ & 0.295 & 0.669 \\
\hline
\end{tabular}

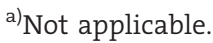




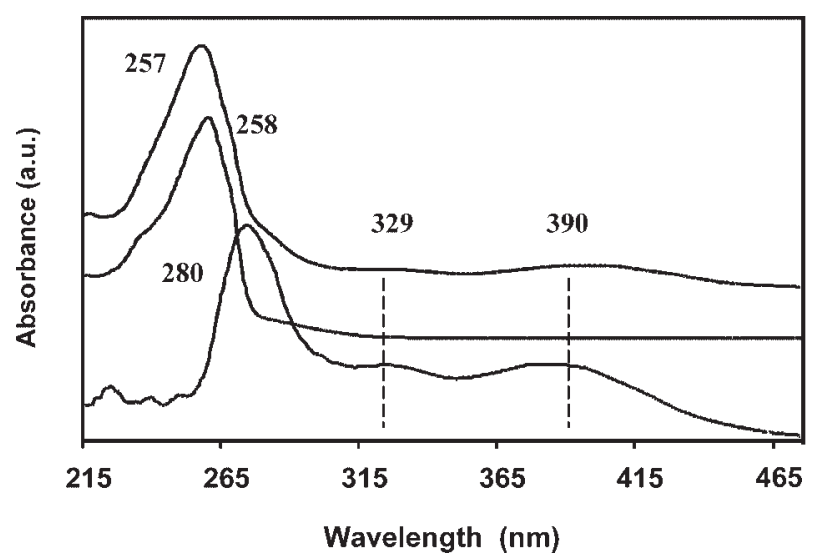

Figure 5. UV-vis spectra of modified alizarin, diblock copolymers PBA- $b$-PS and PBA- $b-\mathrm{P}$ (S-A) (from bottom to top).

of affinity with the bulk. Indeed, when the polymer chains grow from the mica surface, the intermolecular interactions with the free macromolecular chains of the external solution should be higher than the ionic interactions between the end chains and the mica surface. The calorimetric behavior of the PBA- $b-\mathrm{P}(\mathrm{S}-\mathrm{A})$ bound to mica was scanned and the DSC trace of the composite has shown two glass transitions $\left(T_{\mathrm{g}}\right)$ at -42 and $92^{\circ} \mathrm{C}$, which correspond to the transitions of PBA and PS segments, respectively. These results are in agreement with the formation of the diblock copolymer. Indeed, the normal $T_{\mathrm{g}}$ of PBA is around $-55^{\circ} \mathrm{C}$. In this case, one of the ends of the PBA is adsorbed on the mica surface and the other end is covalently bonded to the PS segment of the diblock copolymer in a glassy state. In this type of organization, the PBA block is confined between two 'solid' phases and its $T_{\mathrm{g}}$ increases. On the other hand, the $T_{\mathrm{g}}$ of $\mathrm{P}(\mathrm{S}-\mathrm{A})$ was lower than that expected for pure PS of the same molecular weight. An identical effect has already been observed with PBA-b-PS diblock-grafted silica particles, which demonstrates that it can be attributed to the linkage of PS with the 'soft' phase of PBA, which decreases its $T_{\mathrm{g}}$ value. ${ }^{[9]}$ Recalling that the main objective of this study was to create polymer layers from the mica surface while preserving its lamellar structure, it was checked if the layers of this structure were damaged during the process. The XRD patterns of the resulting solid prepared by polymerization from the mica surface of PBA and PBA- $b-\mathrm{P}(\mathrm{S}-\mathrm{A}) / \mathrm{mica}$ hybrids are compared to pure mica in Figure 6.

In the different XRD patterns, it is observed that the peak corresponding to the (001) reflection of mica is not perturbed by the different pigment synthesis steps. The treatments carried out on the compound relative to mica did not seem to affect its lamellar structure, and also preserved its optical properties.

The purpose of this study was to prepare new pigments with different colors from the substrate and to exhibit

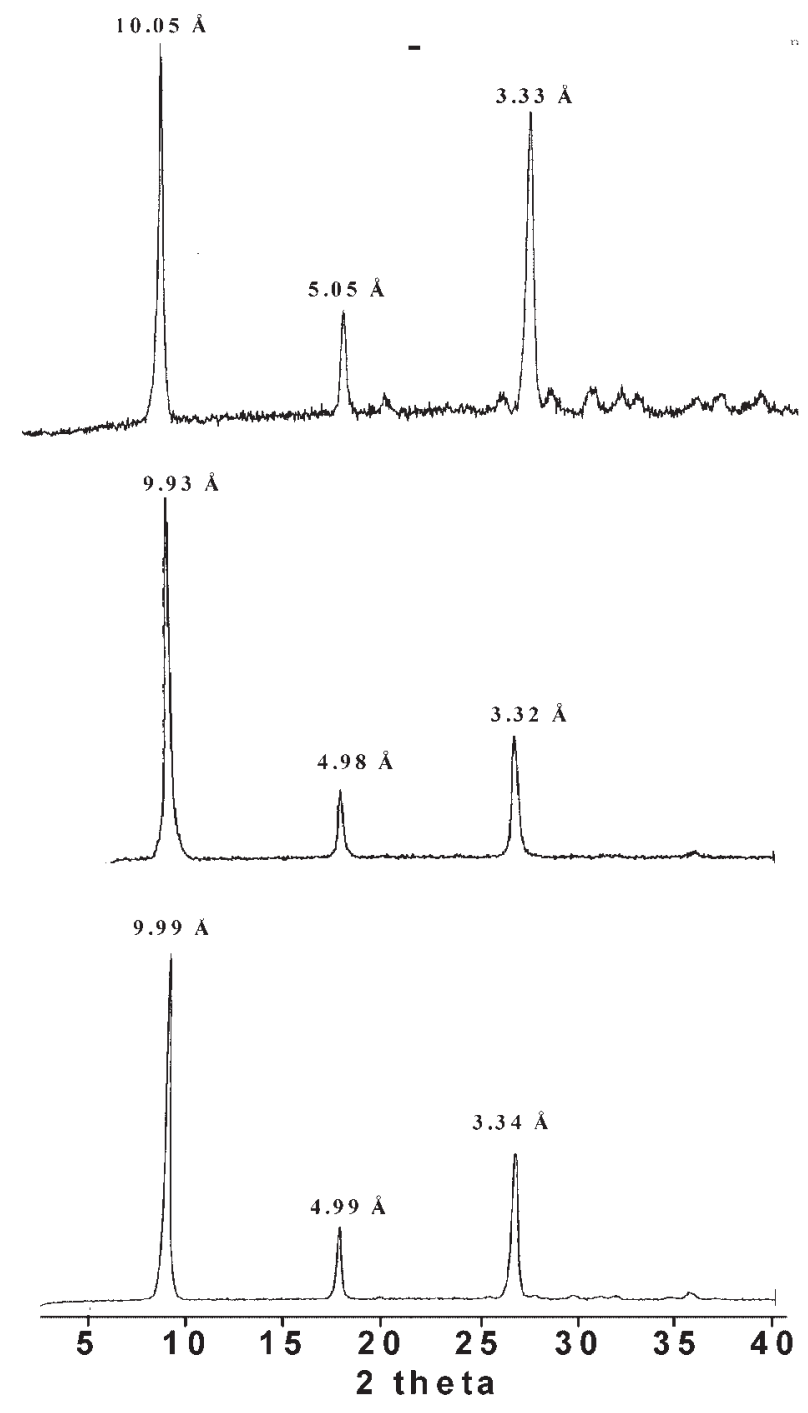

Figure 6. X-Ray diffraction patterns of Soft Mica ${ }^{\circledR}$, PBA-coated mica, and diblock copolymer PBA- $b-\mathrm{P}(\mathrm{S}-\mathrm{A})-\mathrm{mica}$ colored hybrid, respectively, from bottom to top.

interferential effects. As shown by photographs (a) to (c) in Figure 7, the change of mica color by polymer and copolymer adsorption is quite remarkable. First, on the basis of a 'white' Soft Mica (Figure 7a), the adsorption of a layer of PBA on this silicate gives a 'pale yellow' product (Figure $7 b$ ), which could be attributed to the effect of coating the mica by an adsorbed monolayer of polymer. Next, the addition of a new layer of P(S-A) gives a 'pink' organic/inorganic hybrid (Figure 7c).

The color modification generated by the nature of the organic layer on the mica surface is confirmed by the UV-vis spectra in the solid state. For the 'white' Soft Mica, a classical adsorption spectrum is obtained with an intense peak centered at $260 \mathrm{~nm}$. When the mica surface is coated by a PBA layer, a broad adsorption peak appears from $450 \mathrm{~nm}$ with a maximum at $360 \mathrm{~nm}$, characteristic of a 


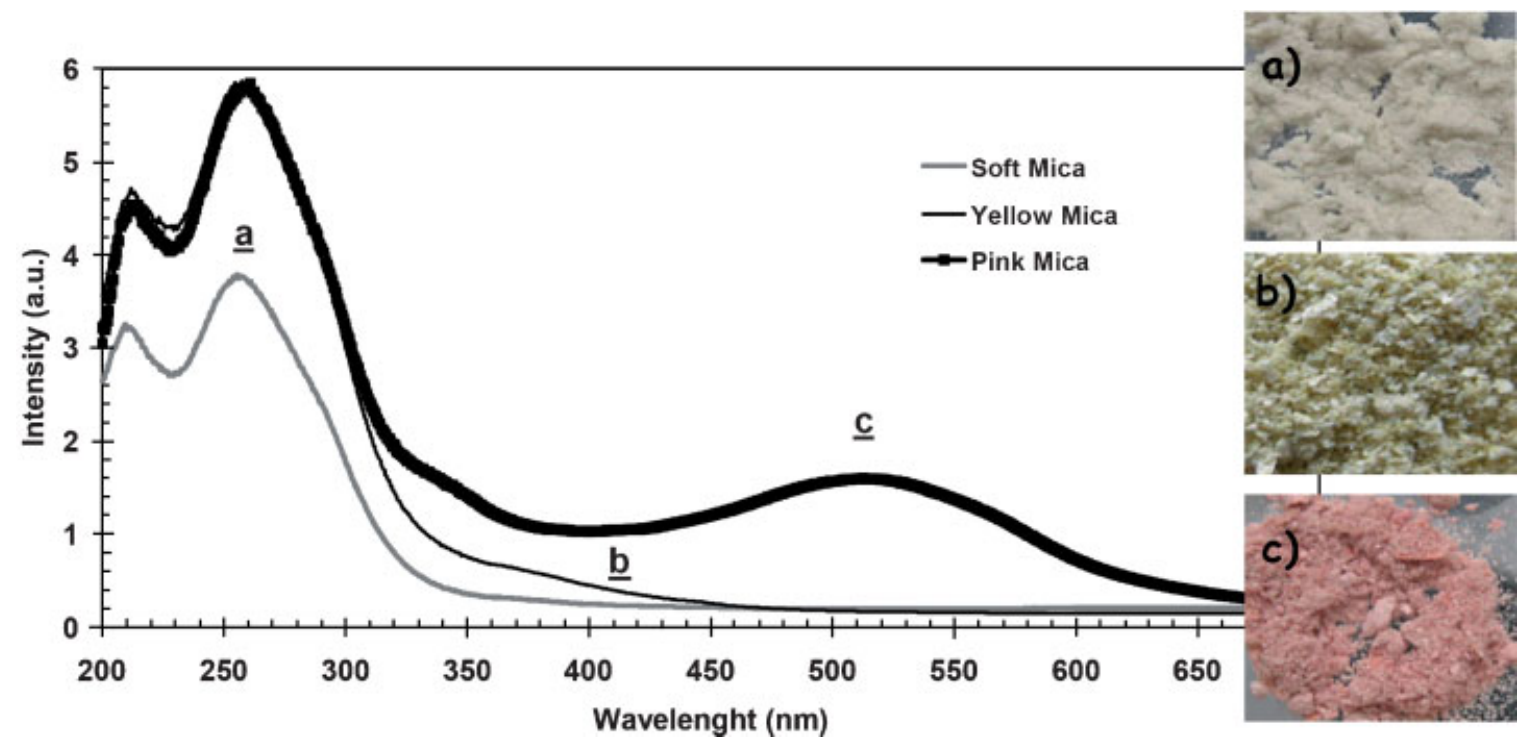

Figure 7. Photographs and UV-vis spectra in solid state of Soft Mica ${ }^{\circledR}$ (a), yellow PBA-mica hybrid (b), and pink diblock copolymer PBA- $b-\mathrm{P}(\mathrm{S}-\mathrm{A})$-mica hybrid (c).

yellow coloration. Moreover, the PBA-b-P(S-A) layer shows an intense absorption at $510 \mathrm{~nm}$ and confirms the pink color of such a mica hybrid. Considering that the free diblock copolymer PBA- $b$-P(S-A) in the form of a powder is yellow, the pink color of the copolymer/mica hybrid is quite surprising. Indeed, it may be that in the hybrid, the dye is influenced by the mica surface. As previously described, the mica surface has a basic character and the dye color is $\mathrm{pH}$ sensitive (Figure 8). The pink color could correspond to a local basic $\mathrm{pH}$ or electronic environment of the dye. ${ }^{[8 b]}$

From simple visual observation, no interference effects of these new pigments has been identified. Several explanations can be proposed: i) the difference between the

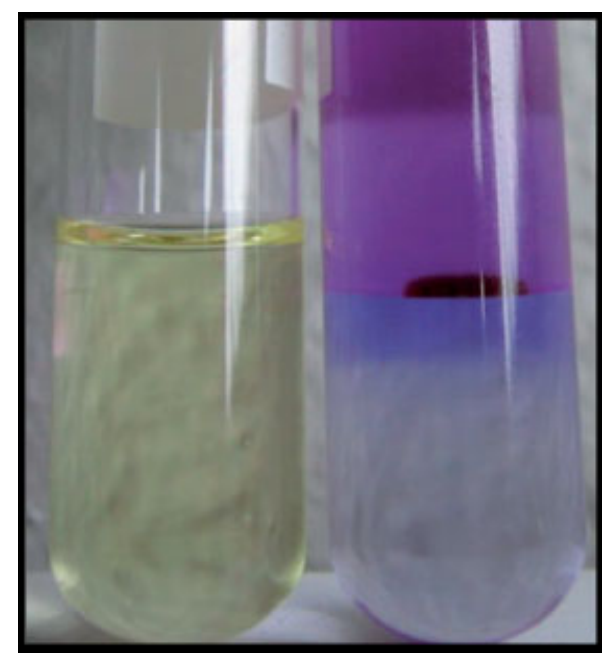

Figure 8. Photographs of $\mathrm{P}(\mathrm{S}-\mathrm{A})$ solubilized in THF before and after addition of basic water solution, respectively from left to right. refractive indices of the two polymer layers is not large enough $\left(n_{\mathrm{PS}}=1.55\right.$ and $\left.n_{\mathrm{PBA}}=1.47\right)$, and ii) the thickness of these layers is too small. The second point has to be consistent with the pink color of the copolymer mica composite attributed to the location of the dye in the immediate vicinity of the mica surface. Nevertheless, we have demonstrated the ability of the NMP to generate block copolymers from the mica surface in order to elaborate a new organic/inorganic hybrid pigment type based on mica.

Since the color of the free PBA- $b-\mathrm{P}(\mathrm{S}-\mathrm{A})$ diblock (not adsorbed on mica) was yellow, it was supposed that the pink color of the hybrid obtained could be a result of: i) the $\mathrm{pH}$ dependence of the dye (modified alizarin), and ii) the effect of oxanions of the mica surface. As such, we attempted the preparation of colored hybrid P (S-A)-mica materials by direct NMP of styrene and the modified alizarin. The adsorption density of the polymer on mica surface and the effective color of the $\mathrm{P}(\mathrm{S}-\mathrm{A})$-mica hybrid is discussed.

The mica surface was modified by a cationic initiator and styrene with a low content of alizarin (A) was copolymerized from the initiator-bounded mica. For this purpose, a mixture of AIBA-adsorbed mica particles (166 mg) (1.5 $\mu \mathrm{mol}$ per mg of mica), styrene (estimated ratio [S]/ $2[\mathrm{AIBA}]=500)$, SG1 (slight excess $([\mathrm{AIBA}] /[\mathrm{SG} 1]=2.1))$, and modified dye $([\mathrm{S}] /[\mathrm{A}]=333)$ was heated at $120^{\circ} \mathrm{C}$ for 1,2 , and $4 \mathrm{~h}$. The molecular weight of the free $\mathrm{P}(\mathrm{S}-\mathrm{A})$ polymers obtained after 1, 2, and 4 hours are described in Table 1.

One simple test was performed to confirm the incorporation of modified dye into the polymer chains. Alizarin being a water soluble dye, some drops of $\mathrm{NaOH}(1 \mathrm{M})$ were added to $\mathrm{P}(\mathrm{S}-\mathrm{A})$ in THF solution until phase separation. 

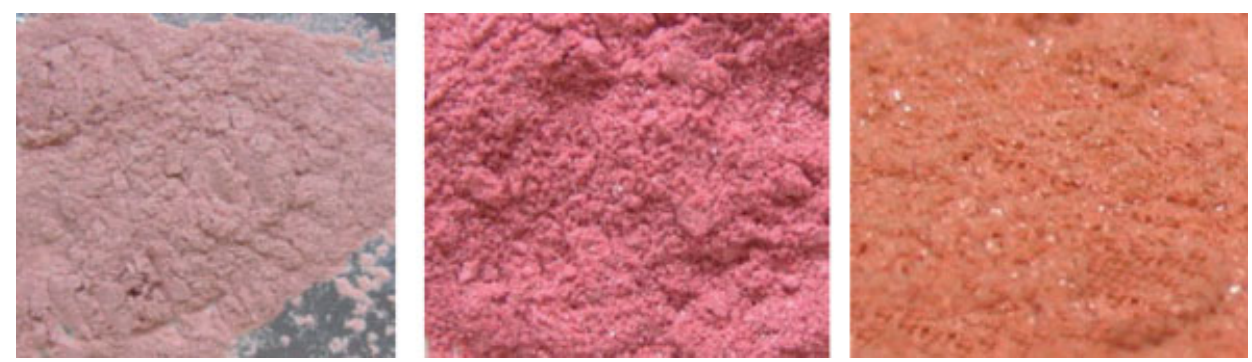

Figure 9. Photographs of $\mathrm{P}(\mathrm{S}-\mathrm{A})$-mica hybrids for 1, 2, and 4 hours of polymerization, from left to right.

A colored organic polymer phase (purple) (top, THF $d=0.89$ ) and non-colored aqueous phase (below, water $d=1$ ) were observed and the result confirmed by no adsorption of the aqueous phase by UV-vis spectroscopy. This phenomena meant that any traces of the free dye are present in the aqueous phase (Figure 8).

Moreover, it is quite clear that if the $\mathrm{P}(\mathrm{S}-\mathrm{A})$ is yellow colored in the THF phase. This color can be easily tuned by addition of a base or by modification of the electrostatic state of the grafted alizarin to purple. Figure 9 shows another very interesting result, which consists of the variation of color of different hybrids depending on polymerization time. We have found that the color becomes 'darker and darker' with an increasing of polymerization time. This can be explained by either the increase of A units incorporated into the polymer chains or by the decrease of adsorption density of polymer ( $\sigma_{\text {ads }} \mu$ mole per mg of mica) on the mica surface (Table 1).

For hybrids obtained after 1 and $2 \mathrm{~h}$ of polymerization, their $\sigma_{\text {ads }}$ are comparable $\left(4.4 \times 10^{-3}\right.$ and $5.4 \times 10^{-3} \mu$ mole per mg of mica, respectively, Table 1 ). The colour variation observed between these two composites can be directly related to the quantities of alizarin incorporated into polymer chains: the more incorporated alizarin, the darker the observed colour.
The pigment color can then be tuned by adjustment of the length and grafting density of, and also the number of dye molecules incorporated in, the chains. This new hybrid pigment can also be used as a filler in cosmetic or coatings applications.

Moreover, it was possible to check the interferential optical phenomena by spectrophotogoniometry. A schematic description of this technique is represented in Figure 10 (left). When a surface is illuminated at a specific angle with a white light, with the same characteristic as the sun, the light is reflected by the surface and it is possible to recover at different angles the colorimetric parameters $a^{*}$ (green to red) and $b^{*}$ (yellow to blue) (norm CIE 1976). Figure 10 (right) presents the variation of the colorimetric parameters $a^{*} / b^{*}$ obtained for two incident angles of illumination and recovered between 0 and $60^{\circ}$.

The perception of the pigment color can be shifted from pink to orange by playing with the angle of observation of such a pigment (Figure 10 right). In this case, a slight interferential effect was obtained because of the low refractive index of the PS monolayer on the mica surface. Some improvements are underway in order to increase the thickness, and hence the value of the refractive indexes of the organic layers that coat the inorganic surface of the mica particles.
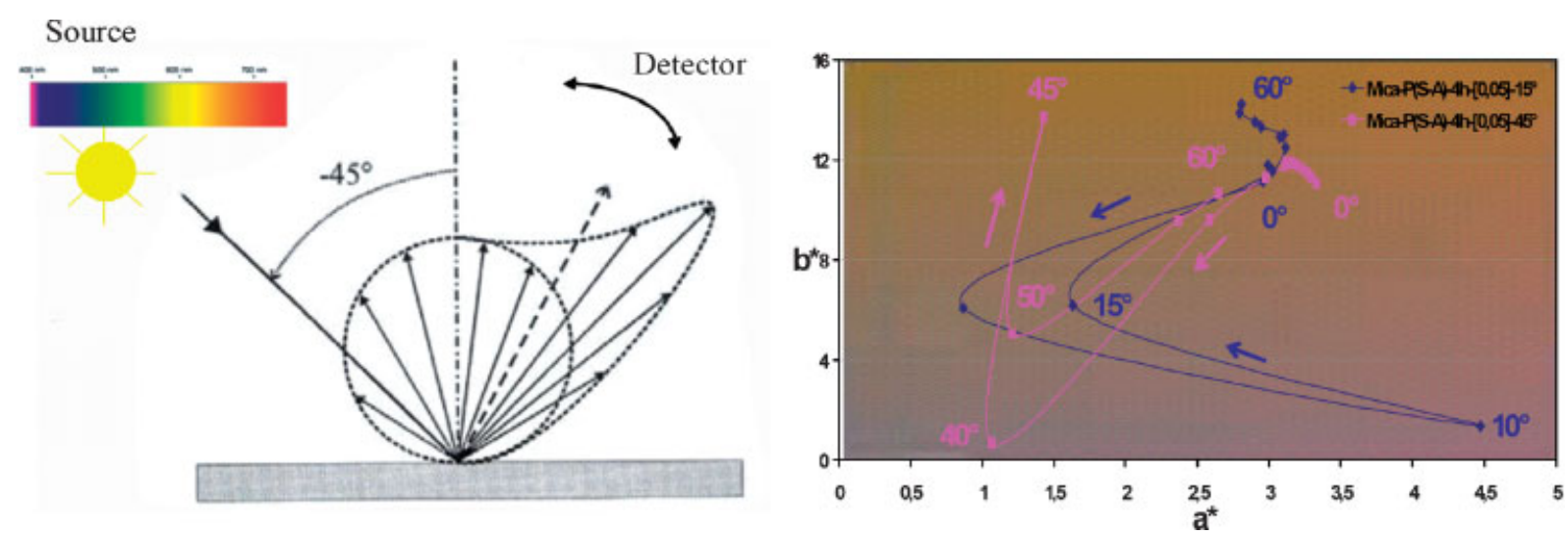

Figure 10. Principle of the spectrophotogoniometry with an incidence angle of $45^{\circ}$ and colorimetric parameters $a^{*} / b^{*}$ obtained for hybrid pigment $\mathrm{P}(\mathrm{S}-\mathrm{A})$-mica (incidence angle: $15^{\circ}$ and $45^{\circ}$ ), from left to right. 
Finally, an original way to elaborate some organic/inorganic hybrid pigments in order to create interferential optical phenomena has been presented and is able to increase the stability/dispersion in polymeric matrices for cosmetic, paint, or coating applications.

\section{Highly Ordered System: Honeycomb-Like Structure}

François et al. have demonstrated that at least four conditions must be met to create honeycomb struc-
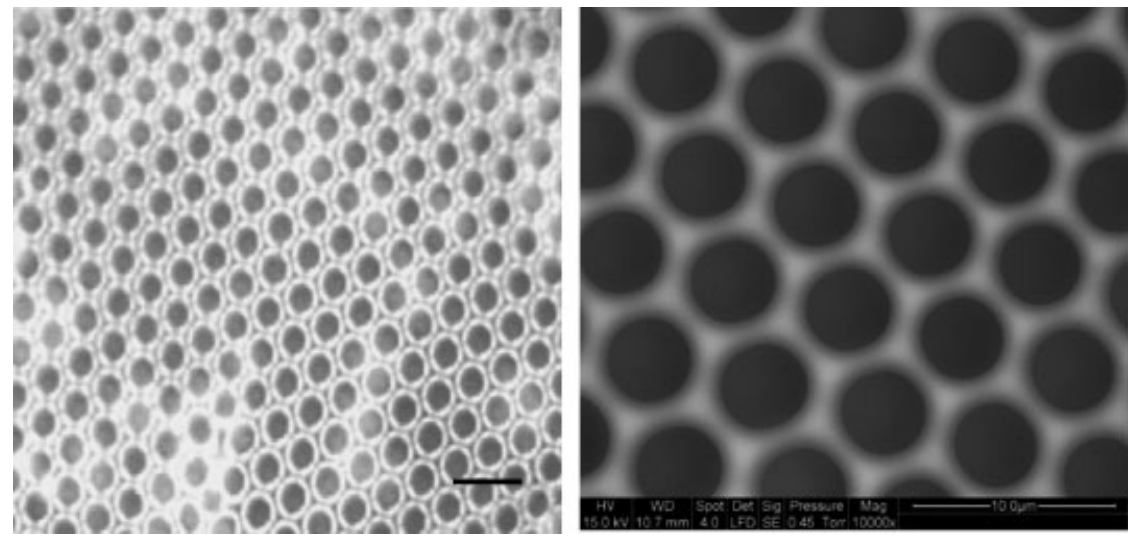

Figure 11. Optical micrographs (scale bare $=10 \mu \mathrm{m})$ (left) and SEM images (10000 $\times$, scale bar $=10 \mu \mathrm{m}$ ) (right) of honeycomb structure of $\mathrm{P}(\mathrm{S}-\mathrm{A})$ on mica sheet. tures: i) a chemical or physical star-like structure must form by auto-association, ii) evaporation of solvent must occur in a wet atmosphere, iii) use of a solvent with a low boiling point and a high boiling enthalpy, and iv) use of water immiscible solvent. For these reasons, $\mathrm{CS}_{2}$ was found to be the best solvent to be used for generating honeycomb films from PS solutions. ${ }^{[10-12]}$

In the present work, polymers have been synthesized easily in a one-step reaction based on two commercial products using the NMP in bulk. A polymeric structure with cationic end chains has been used to create free thermoplastic PS ionomers (high value of $T_{\mathrm{g}} \approx 100^{\circ} \mathrm{C}$ ). This polymer has been synthesized under NMP and the molecular weight and PDI values are $28000 \mathrm{~g} \cdot \mathrm{mol}^{-1}$ and 1.2, respectively.

From this ionomer structure, $\mathrm{CS}_{2}$ polymer solutions have been prepared and simply spread on a mica substrate at room temperature under moist air. This novel and facile route was checked to create highly ordered self-assembled honeycomb films. The optical and SEM images of honeycomb structures obtained by the self-assembly of $\mathrm{P}(\mathrm{S}-\mathrm{A})$ on the mica substrate are presented in Figure 11.

These photos present very uniform pores in size and spatial arrangement on mica. Images show that a honeycomb structure in hexagonal arrays is observed on a freshly cleaved mica surface over a long-range distance (few hundred micrometers). These ionomer macromolecular structures lead to a very homogeneous pore size of $4 \mu \mathrm{m}$. This could be explained by high electrostatic interactions between the anionic mica surface and the cationic ionomer. In fact, the electrostatic interac-

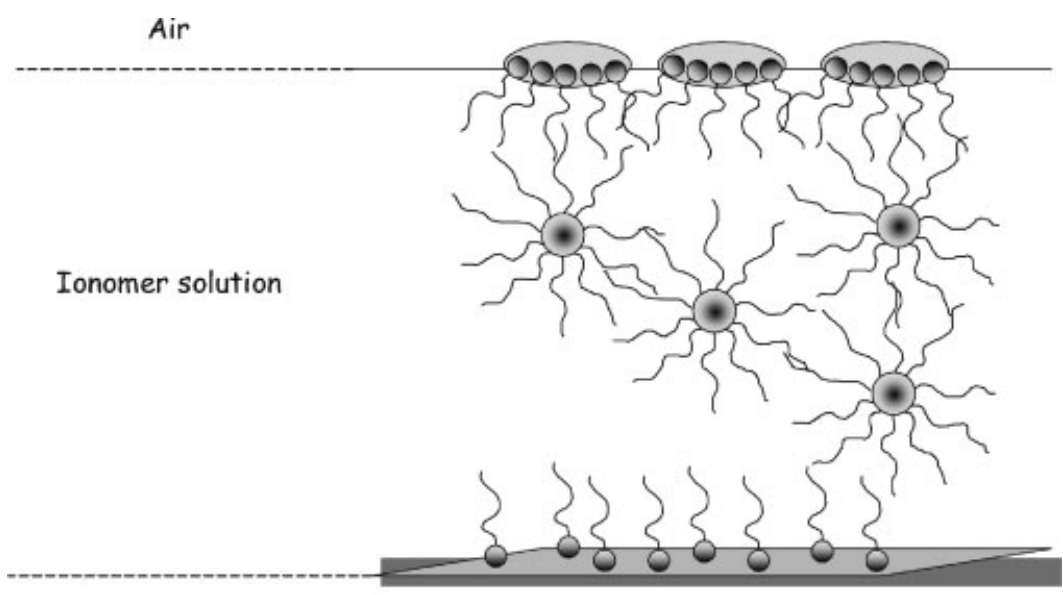

Mica sheet

tions between oxanions of the mica surface and the cationic end of ionomers could limit the chains mobility as well as the microdroplets mobility and give a regular structure on mica surface. The long-range ordered array is then driven by competition of repulsive and attractive forces, which leads to a water/polymer solution interface filled with water droplets. The droplets are stabilized by a solvated polymer layer and a polymer solution/solid interface stabilized by ionic interactions. All these critical interactions are important for these materials systems, which include water/solvent (immiscibility), water/ionomers (only the cationic end groups are water soluble), solvent/ionomer (only the PS blocks are soluble and cationic end groups aggregate to form star-like micelles), and ionomer/mica substrate interactions (strongly elec- 
trostatic attraction $\left.{ }^{[8,20]}\right)$. This complex situation is schematicized in Figure 12.

This mechanism is compatible with the process described by Srinivasarao et al. ${ }^{[21]}$ and Karthaus et al. ${ }^{[22]}$ since we have observed a turbid top layer on the polymer solution associated with water droplets condensation. This step was followed by the fast evaporation of the $\mathrm{CS}_{2}$, which led to a cooling of its surface because of the heat of the evaporation, and water condenses onto this surface. The sub-phase of $\mathrm{CS}_{2}$ was mobile and a close packing of water droplets was obtained in a hexagonal arrangement. Moreover, they mentioned that a crucial point for the formation of a regular honeycomb pattern was the prevention of the coalescence of the water droplets. ${ }^{[22]}$ This can be achieved either by thermodynamic or by kinetic control: 1) the thermodynamic control involved the stabilization of the water droplets by surface-active compounds, i.e., ionomers as amphiphilic molecules with a hydrophilic head and a hydrophobic tail (Figure 12). 2) Dynamic control was achieved by using a highly volatile solvent that ensures a rapid evaporation so that the water droplets have no time to coalesce before the complete evaporation of the CS2 solvent. This rapid evaporation led to a large temperature difference between the water droplets and the solvent, which induced a thermocapillary convection and stabilized the condensing water droplets on the polymer solution surface. ${ }^{[21]}$ Different works are underway to check the influence of different types of ionomers correlated with the polymer concentration and the thickness of the wet film.

Moreover, sun-flower patterns can be also obtained on fresh mica sheets using a thermoplastic P(S-A) (Figure 13). The origin of such a pattern is not well understood at this time of the study. It could be caused by the presence of defaults on the freshly cleaved mica surface acting as nucleating agents.

Moreover, we have observed other interesting phenomena. A color diffraction can be originated from the regularity of such a honeycomb-structured surface. This effect

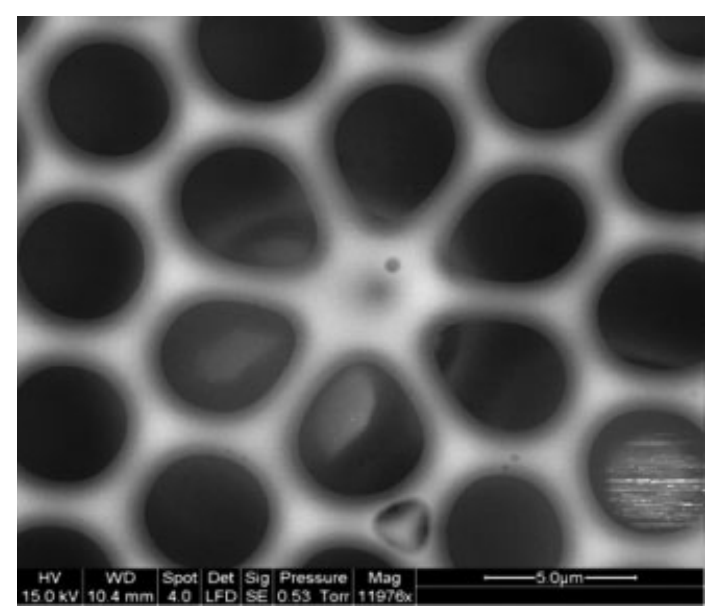

Figure 13. Sun-flower patterns by the self-assembly of ionomer $\mathrm{P}(\mathrm{S}-\mathrm{A})$ on mica sheet $(12000 \times$, scale bar $=5 \mu \mathrm{m})$.

can be obtained from a large film obtained over a largerange distance as described in Figure 14.

This microsized-patterned honeycomb structure decomposes the sunlight and creates a rainbow on the flat surface. This interferential optical phenomena was created by a simple tilt of the mica sheet to diffract the sun light. A more precise study is shown in Figure 14 (right). The perception of the color can be highly shifted from blue through purple to green by playing with the angle of observation of such structured films. Moreover, with the same structured surface but with an incidence angle of $45^{\circ}$, the colors can be modulated from pink through orange to green. In this case, a high interferential effect is obtained because of the strong diffraction of the light onto this highly structured system. This phenomenon can be used to tune perception of the colored surface as pure inorganic pearlescent pigments. This highly ordered hexagonal pattern suggests the possibility of taking advantage of the micro textures for inducing optical interferences but also to modify the colour of material as a function of their visual angle as in Nature. This approach could represent a
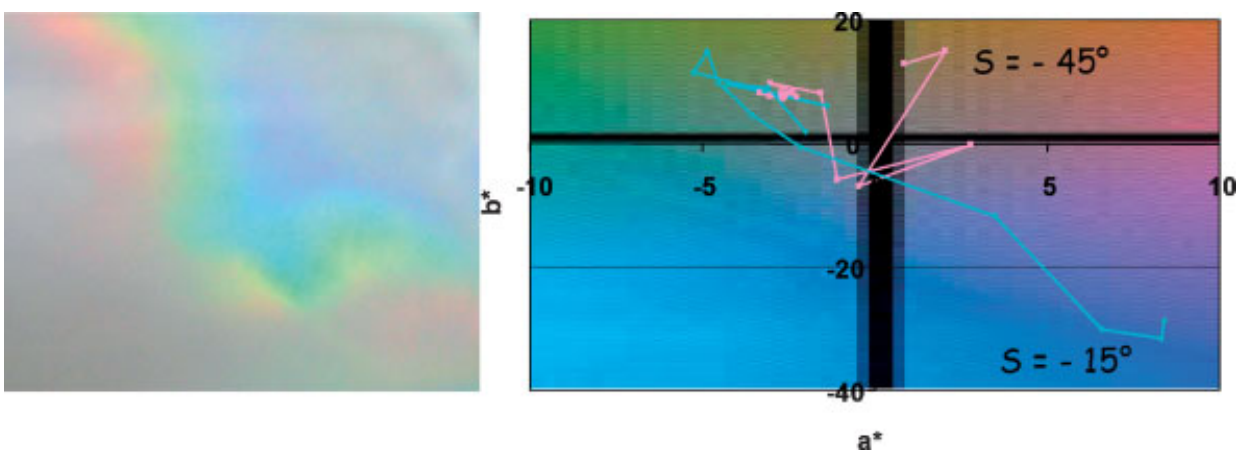

Figure 14. Photograph of iridescent visual effect and colorimetric parameters $a^{*} / b^{*}$ (incidence angles $15^{\circ}$ and $45^{\circ}$ ) obtained from a honeycomb self-structured polymer film on a mica sheet $\left(3 \times 2 \mathrm{~cm}^{2}\right)$. 
facile route to honeycomb structures and biomimics of Nature's materials with specific properties.

\section{Conclusion}

This paper describes a relatively simple method to prepare an organic/inorganic hybrid pigment constituted of mica platelets and adsorbed polymer layers. The color of mica is changed upon polymer adsorption and when one of the copolymer sequences includes a dye, its color is influenced by the chemical properties of the mica surface. Though these new pigment types exhibit a slight interferential effect, neither the choice of the initial monomers nor the thickness of each sequence have been optimized to produce such effects. From the general pathways described in this paper, it may be possible to monitor the visual aspect of these pigments by selected experimental conditions of the in-situ nitroxide-mediated copolymerization.

Beside all the complex techniques present to elaborate honeycomb structures, a new facile route to obtain highly ordered surfaces that uses ionomer macromolecular systems synthesized in one step using bulk CRP without solvents has been presented. The preparation of films with very regular pore size and spatial organization has been successfully realized by using an ionomer solution synthesized by NMP. An original property of these films is described with the iridescent color obtained by light diffraction thanks to the optical interferences of sunlight with the periodic honeycomb structures. The domain of applications of these films is very large and has still to be explored, especially towards optical visual effects. All these new materials based on polymeric controlled structures can reproduce nature by creating an optical interferential and iridescent material, which offers new fascinating applications as original bio-mimetic materials on organic or inorganic surfaces.

Acknowledgements: The authors thank B. François for his scientific discussion and P. Maury from 2PSM "Propriétés Psychosensorielles des Matériaux" for his support and motivation.

Keywords: honeycomb structures; living polymerization; monolayers; organic/inorganic hybrid material; self-organization
[1] C. D. Bain, G. M. Whitesides, J. Am. Chem. Soc. 1988, 110, 5897.

[2] Y. T. Tao, J. Am. Chem. Soc. 1993, 115, 4350.

[3] A. Ulman, D. K. Schwartz, J. T. Woodward, Langmuir 1996, $12,3626$.

[4] [4a] T. Lan, T. Pinnavaia, J. Chem. Mater. 1994, 6, 6221; [4b] Z. Wang, T. Pinnavaia, Chem. Mater. 1998, 10, 1820.

[5] U. Velten, S. Tossati, R. A. Shelden, W. R. Caseri, U. W. Suter, Langmuir 1999, 15, 6940.

[6] K. Matyjaszewski, "Advances in Controlled/Living Radical Polymerization", ACS Symp. Ser., Vol. 854, American Chemical Society, Washington, DC 2003.

[7] [7a] J. Parvole, G. Laruelle, C. Guimon, J. Francois, L. Billon, Macromol. Rapid Commun. 2003, 24, 1074; [7b] J. Parvole, J. P. Montfort, L. Billon, Macromol. Chem. Phys. 2004, 205, 1369; [7c] R. Inoubli, S. Dagreou, F. Roby, A. Khoukh, J. Peyrelasse, L. Billon, Polymer 2005, 46, 2486; [7d] R. Inoubli, S. Dagreou, A. Lapp, L. Billon, J. Peyrelasse, Langmuir 2006, 22,6683

[8] L. Ghannam, M. Bacou, H. Garay, J. Francois, M. E. R. Shanahan, L. Billon, Polymer 2004, 45, 7035.

[9] G. Laruelle, J. Parvole, J. François, L. Billon, Polymer 2004, 45, 5013.

[10] G. Widawski, M. Rawiso, B. François, Nature 1994, 369, 387.

[11] B. François, O. Pitois, J. François, Adv. Mater. 1995, 7, 1041.

[12] B. François, Y. Ederlé, C. Mathis, Synth. Met. 1999, 103, 2362.

[13] M. H. Stenzel, T. P. Davis, A. G. Fane, V. Chen, Angew. Chem., Int. Ed. 2001, 40, 3428.

[14] Y. Xu, B. K. Zhu, Y. Y. Xu, Polymer 2005, 46, 713.

[15] B. de Boer, U. Stalmach, H. Nijland, G. Hadziioannou, Adv. Mater. 2000, 12, 1581.

[16] T. Nishikawa, J. Nishida, R. Ookura, S. Nishimura, V. Scheumann, M. Zizlsperger, R. Lawall, W. Knoll, M. Shimomura, Langmuir 2000, 16, 1337.

[17] C. Cheng, Y. Tian, Y. Shi, R. Tang, F. Xi, Macromol. Rapid Commun. 2005, 26, 1266.

[18] A. Böker, Y. Lin, K. Chiapperini, R. Horowitz, M. Thompson, V. Carreon, T. Xu, C. Abetz, H. Skaff, A. D. Dinsmore, T. Emrick, T. P. Russel, Nat. Mater. 2004, 3, 298.

[19] U. H. F. Bunz, Adv. Mater. 2006, 18, 973.

[20] L. Ghannam, H. Garay, M. Shanahan, J. François, L. Billon, Chem. Mater. 2005, 17, 3837.

[21] M. Srinivasarao, D. Collings, A. Philips, S. Patel, Science 2001, 292, 79.

[22] O. Karthaus, N. Maruyama, X. Cieren, M. Shimomura, H. Hasegawa, T. Hashimoto, Langmuir 2000, 16, 6071. 